\title{
Release and Complex Formation of Soluble VEGFR-1 from Endothelial Cells and Biological Fluids
}

\author{
Carsten Hornig, Bernhard Barleon, Shakil Ahmad, Piia Vuorela, Asif Ahmed, and \\ Herbert A. Weich
}

National Research Center for Biotechnology (CH, HAW), Department RDIF, Braunschweig, Germany; Institute of Molecular Medicine (BB), Tumor Biology Center, Freiburg, Germany; Department of Reproductive and Vascular Biology (SA, AA), Division of Reproductive and Child Health, University of Birmingham, Birmingham, United Kingdom; Department of Obstetrics and Gynecology (PV), Helsinki University Central Hospital, Helsinki, Finland

SUMMARY: One of the key molecules promoting angiogenesis is the endothelial cell-specific mitogen, vascular endothelial growth factor (VEGF or VEGF-A), which acts through two high-affinity receptor tyrosine kinases (VEGFR), VEGFR-1 (or Flt-1) and VEGFR-2 (or KDR/Flk-1). It was shown before that a soluble variant of VEGFR-1 (sVEGFR-1) can be generated by differential splicing of the flt-1 mRNA. This soluble receptor is an antagonist to VEGF action, reducing the level of free, active VEGF-A, and therefore, plays a pivotal role in the generation of vascular diseases like pre-eclampsia or intra-uterine growth retardation. Here we show that SVEGFR-1 is produced by cultured human microvascular and macrovascular endothelial cells and a human melanoma cell line. The soluble receptor is mainly complexed with ligands; only $5-10 \%$ remains detectable as free, uncomplexed receptor protein. Furthermore, we show the time course of total and free sVEGFR-1 release together with its putative ligands, VEGF-A and placenta growth factor (PIGF), from macrovascular endothelial cells. The release of sVEGFR-1 was quantitatively measured in two different ELISA types. The release of SVEGFR-1 was strongly enhanced by phorbol-ester (PMA); the cells produced up to $22 \mathrm{ng} / \mathrm{ml}$ of sVEGFR-1 after 48 hours. The expression of VEGF-A and PIGF was moderately influenced by PMA. We also show a hypoxia-induced increase of sVEGFR-1 expression in cells cultured from placenta, a tissue that has a high flt-1 gene expression. Moreover, we demonstrate that sVEGFR-1 in amniotic fluids acts as a sink for exogenous VEGF ${ }_{165}$ and PIGF-2. Here, for the first time, to what extent recombinant ligands have to be added to compensate for the sink function of amniotic fluids was analyzed. In conclusion, human endothelial cells produce high levels of sVEGFR-1, which influences the availability of VEGF-A or related ligands. Therefore, sVEGFR-1 may reduce the ligand binding to transmembrane receptors and interfere with their signal transduction. (Lab Invest 2000, 80:443-454).

$T$ he vascular system of the embryo is formed by a process termed vasculogenesis that involves determination and differentiation of hemangioblastic cells and their assembly into a primitive vascular plexus (Flamme et al, 1997). In the adult organism, sprouting of new capillaries, termed angiogenesis, is implicated in several physiologic and pathophysiologic situations (Ferrara and Davis-Smyth, 1997). The angiogenic process is influenced by a delicate balance of endogenous positive and negative regulators. One of the key players promoting angiogenesis is the endothelial cell-specific mitogen vascular endothelial growth factor (VEGF or VEGF-A) (Leung et al, 1989). VEGF-A mediates its signals through the receptor tyrosine kinases (VEGFR), VEGFR-1 (or Flt-1) (Shibuya et al, 1990) and VEGFR-2 (or KDR) (Terman et al, 1992). VEGFR-3 (Pajusola et al, 1992), and its ligand,

Received February 1, 2000.

This work was supported by the EU Biomed II network "Angiogenesis and Cancer" (PL 950669) and by grants from British Heart Foundation (RG/98003) and Wellcome Trust (053347/B/98).

Address reprint requests to: $D r$. H. A. Weich, National Research Center for Biotechnology (GBF), Department RDIF, Mascheroder Weg 1, 38124 Braunschweig, Germany. Fax: 495316181 202; E-mail:weich@gbf.de
VEGF-C, are mainly associated with lymphangiogenesis. Additional ligands for VEGFR-1 are placenta growth factor (PIGF) and VEGF-B (Olofsson et al, 1998). VEGFR-1 has a higher affinity for the different VEGF forms than VEGFR-2, but VEGFR-1 shows a weaker ligand-dependent tyrosine phosphorylation than VEGFR-2 (Seetharam et al, 1995). Knockout experiments have strongly implicated both VEGFR-1 and VEGFR-2 in the development of the embryonic vasculature (Fong et al, 1995; Shalabi et al, 1995). VEGFR-1-deficient mice did not survive beyond embryonic day 9.5, showed an abnormal morphology of endothelial cells and the vascular wall, and endothelial cells accumulated within the blood vessels (Fong et al, 1995). A recent report demonstrates that the embryo seems to develop normally when only the kinase domain of VEGFR-1 is deleted and the extracellular domains and transmembrane region are left intact (Hiratsuka et al, 1998). This situation might leave cells with the ability to synthesize transmembrane and soluble receptors. VEGFR-2-deficient mice had no mature endothelial cells, and the hematopoietic development was severely impaired (Shalabi et al, 1995). Thus, VEGFR-2 plays an important role in much earlier time points of development than VEGFR-1. 
Transmembrane and soluble forms of VEGFR-1 are found in non-endothelial cells (eg, monocytes), where they mediate chemotaxis and migration (Clauss, 1998); on human trophoblast cells, where they stimulate calcium-dependent nitric oxide release (Ahmed et al, 1997); and in dendritic cells, where VEGF-A can inhibit functional maturation (Gabrilovich et al, 1996). The cDNA of a soluble VEGFR-1 (sVEGFR-1) has been cloned (Kendall and Thomas, 1993), although no naturally occurring soluble forms of VEGFR-2 or VEGFR-3 have been reported. The soluble receptor seems not to be generated by proteolysis on the cell surface. It is a splice variant of the flt-1 gene consisting of the extracellular immunoglobulin-like domains 1 to 6 and a unique $\mathrm{C}$-terminal extension of 31 amino acids derived from an intron sequence. Two novel cDNAs encoding a truncated sVEGFR-1 D1-5 were cloned from ovarian carcinoma cell lines (Boocock et al, 1995). The first three extracellular domains are responsible for high-affinity ligand binding and the fourth domain is important for receptor dimerization (Barleon et al, 1997). The first purification of sVEGFR-1 was described from HUVEC-conditioned media (CM) (Kendall et al, 1996). The soluble receptor bound strongly to heparin-sepharose and had a very high affinity $\left(\mathrm{K}_{\mathrm{d}} \sim 10 \mathrm{pm}\right)$ for VEGF-A. Interestingly, this soluble receptor is also found in mice and has a high degree of homology to the human sVEGFR-1 (Kondo et al, 1998). Recent studies suggest that sera and amniotic fluids from pregnant women contain a highaffinity VEGF-binding protein that acts as a sink for VEGF-A (Banks et al, 1998). After purification from amniotic fluids, this protein was identified as sVEGFR-1 forming high molecular weight complexes with ligands.

More recent studies hypothesize that sVEGFR-1 is a negative regulator of VEGF availability. Therefore, we designed experiments to characterize cell types that produce sVEGFR-1 and to characterize the kinetics of the release of sVEGFR with its possible ligands during cell culture. Furthermore, we investigated the expression and regulation of SVEGFR-1 in the placenta, because sVEGFR-1, as an endogenously secreted VEGF receptor, may be involved in the generation of placental vascular disorders (eg, pre-eclampsia). Moreover, we attempted to clarify the role of sVEGFR-1 in amniotic fluids, which contain high amounts of this soluble receptor.

\section{Results}

\section{Secretion and Detection of sVEGFR-1 Produced by Different Cell Types}

We analyzed the conditions under which different cell types secrete sVEGFR-1 into the media, as well as how the production of the soluble receptor is regulated. sVEGFR-1 was detectable in supernatants of primary HUVEC, primary human dermal microvascular endothelial cells (MVEC), and COLO-800 melanoma cells. We selected the melanoma line because different melanoma cells were previously shown to express VEGFR-1 (Terman et al, 1994). When 48-hour CM and heparin-sepharose-concentrated media were subjected to Western blot analysis, the sVEGFR-1 released from HUVEC or MVEC had a molecular weight of approximately $110 \mathrm{kd}$ (Fig. 1A). This is in agreement with the findings of Kendall et al (1996). The sVEGFR-1 produced by COLO-800 cells, however, had a higher molecular weight of approximately 120 to $130 \mathrm{kd}$. Recombinantly expressed SVEGFR-1 ${ }_{D 1-6}$ from insect cells has only a simple glycosylation pattern; therefore, it had the lowest molecular weight. The apparent difference in size of sVEGFR-1 from HUVEC and COLO-800 cells is due to a different glycosylation pattern. After deglycosylation, both sVEGFR-1 types were the same size (Fig. 1B, left). The possibility that the larger mass form of COLO-800 sVEGFR-1 is

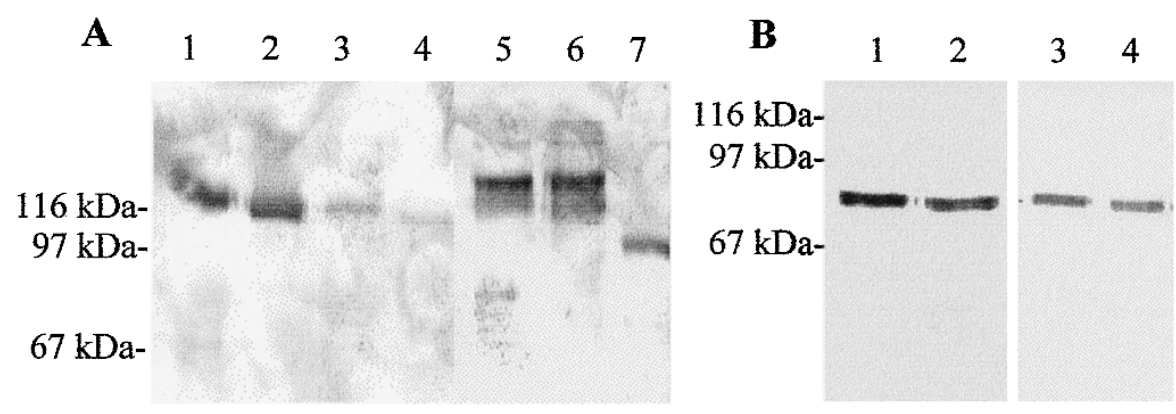

\section{Figure 1.}

Immunoblot showing sVEGFR-1 production by different cell types (A) and deglycosylation of HUVEC-CM and COLO-800-CM (B). A, Five milliliters of serum-free CM from primary HUVEC (lanes 1, 2), primary dermal MVEC (lanes 3, 4), and COL0-800 melanoma cells (lanes 5, 6) were incubated for 2 hours at room temperature with $50 \mu \mathrm{l}$ of heparin-sepharose slurry. After centrifugation the pellet was washed in PBS, and SDS- PAGE sample buffer with (lanes 1, 3, 5) or without mercaptoethanol (lanes 2, 4, 6) was added. Proteins were separated by $10 \%$ SDS-PAGE and transferred to PVDF membrane by semi-dry blotting. The immunoblot was incubated with a mouse monoclonal SVEGFR-1 antibody and an alkaline-phosphatase-conjugated mouse antibody. Lane 7 contains 50 ng of recombinant sVEGFR-1 $1_{\mathrm{D} 1-6}$. The positions of the protein sizes are indicated on the left. $B$, Ten milliliters of HUVEC-CM (lanes 1,3) and COL0-800-CM (lanes 2, 4) were deglycosylated by overnight treatment with $\mathrm{N}$-glycosidase $\mathrm{F}$ at $37^{\circ} \mathrm{C}$, according to the manufacturer's instructions. After incubation with $50 \mu$ l of heparin-sepharose slurry for 2 hours at room temperature and centrifugation, the heparin-sepharose pellets were washed in PBS and boiled in SDS- PAGE sample buffer. Proteins were separated by $10 \%$ SDS-PAGE and transferred to PVDF membrane by semi-dry blotting. The immunoblots were incubated with a mouse monoclonal sVEGFR-1 antibody (lanes 1, 2) or a C-terminal-specific anti-sVEGFR-1 serum (lanes 3, 4), followed by incubation with alkaline-phosphatase-conjugated secondary antibodies. The positions of the protein sizes are indicated on the left. 
generated by proteolysis of the transmembrane receptor was excluded by detection of SVEGFR-1 with an antiserum against the specific C-terminal end of sVEGFR-1 (Fig. 1B, right).

So far, it is not clear to what extent sVEGFR-1 is secreted as free or complexed forms, or which possible ligands are involved in complex formation. Here, we show that sVEGFR-1 concentrated from HUVEC-CM or COLO-800-CM could be cross-linked to ${ }^{125} \mathrm{I}-V E G F_{165}$. Fig. $2 \mathrm{~A}$ shows that HUVEC-CM (lane 5) contains two different complexes of sVEGFR-1, of approximately 140 and $230 \mathrm{kd}$. These could be complexes of one soluble receptor and VEGF (monomer) and two soluble receptors with VEGF (dimer). Interestingly, both the monomer and dimer have higher molecular weights in COLO-800 samples (lane 6). These results indicate that at least a portion of sVEGFR-1 in the CM is free, uncomplexed, and able to form com-

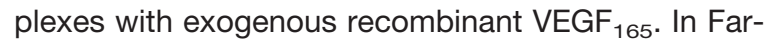
Western experiments, sVEGFR-1 purified from both HUVEC-CM and COLO-800-CM was able to bind iodinated $V_{E G F}$, indicating its potential ability to bind VEGFR-1 ligands even under solid phase conditions (Fig. 2B).

\section{Kinetics of sVEGFR-1, VEGF-A, and PIGF Release from Cultured Endothelial Cells}

We designed time course experiments in which HUVEC were incubated for 3 to 72 hours under different culture conditions. The CM were examined for their sVEGFR-1 content in two different ELISA types, designed to recognize either the total amount of sVEGFR-1 (Hornig et al, 1999), or free, uncomplexed sVEGFR-1 only. The results are shown in Fig. 3. When HUVEC were grown in basal medium, the CM contained approximately $2.5 \mathrm{ng} / \mathrm{ml}$ of sVEGFR-1 after 3

A

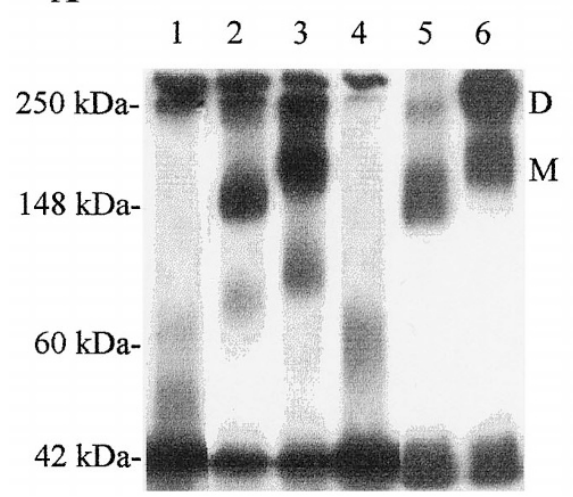

days (Fig. 3A). The amount of free soluble receptor was below the detection limit $(0.5-1 \mathrm{ng} / \mathrm{ml})$. HUVEC cultured in growth medium produced up to $10 \mathrm{ng} / \mathrm{ml}$ of total sVEGFR-1 (Fig. 3B). The amount of free sVEGFR-1 was approximately $2 \mathrm{ng} / \mathrm{ml}$ from 12 hours up to 72 hours, indicating that possible ligands for sVEGFR-1 were produced by HUVEC as well, which may have formed complexes with the soluble receptor. CM from HUVEC grown in basal medium and stimulated with basic fibroblast growth factor (bFGF) contained $5 \mathrm{ng} / \mathrm{ml}$ of sVEGFR-1 after 72 hours, which is a two-fold increase compared with cells grown in basal medium alone (Fig. $3 \mathrm{C}$ ). This shows that bFGF can stimulate the release of SVEGFR-1 into the media. bFGF probably also stimulates the release of potential ligands for the soluble receptors, because the amount of free sVEGFR-1 increased to a constant level. HUVEC stimulated with phorbol-ester (PMA), an activator of protein kinase $C$, produced up to $22 \mathrm{ng} / \mathrm{ml}$ of total sVEGFR-1 (Fig. 3D). The level for the free, soluble receptor increased to $3.5 \mathrm{ng} / \mathrm{ml}$ after 72 hours. The observed up-regulation of sVEGFR-1 expression by PMA and the moderate increase in sVEGFR-1 expression by bFGF were also demonstrated in Northern blotting experiments (Fig. 4). Our results demonstrate that endothelial cells release not only sVEGFR-1, but also release possible ligands of sVEGFR-1 that may form complexes with the soluble receptor protein. However, their regulation seems to be independent of the sVEGFR-1 regulation observed in our experiments.

To address the question of possible ligands for sVEGFR-1, we measured supernatants from the timecourse experiments in VEGF-A and PIGF ELISAs, because it was previously demonstrated that HUVEC produce PIGF (Hauser and Weich, 1993) and low

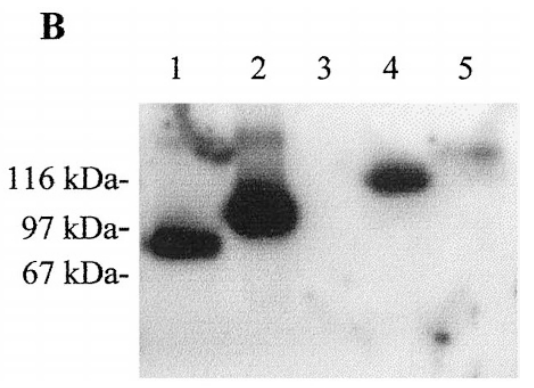

Figure 2.

Covalent cross-linking of iodinated VEGF ${ }_{165}$-sVEGFR-1 complexes (A), and Far-Western with recombinant and naturally occurring sVEGFR-1 from CM (B). A, Human ${ }^{125}$ I-VEGF $_{165}(1 \mathrm{ng})$ was incubated with either purified recombinant sVEGFR-1 or heparin-sepharose concentrated CM at $22^{\circ} \mathrm{C}$ for 2 hours. Iodinated VEGF 165 alone

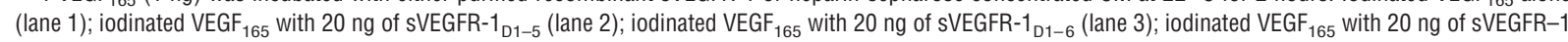
D1-6 and a 50-fold excess of unlabeled VEGF VE5 $_{165}$ (lane 4); iodinated VEGF VE5 $_{165}$ with $5 \mathrm{ml}$ of heparin-sepharose-concentrated HUVEC-CM (lane 5 ); iodinated VEGF with $5 \mathrm{ml}$ of heparin-sepharose-concentrated COL0-800-CM (lane 6). Complexes were covalently cross-linked, separated by 7.5\% SDS-PAGE under non-reducing conditions, and autoradiographed for 24 hours. $D=$ receptor dimer and ligand; $M=$ receptor monomer and ligand. The positions of the protein sizes are indicated on the left. B, Recombinant proteins and heparin-sepharose-concentrated media were separated by $10 \%$ SDS-PAGE under non-reducing conditions and blotted to PVDF membrane. After saturation and three washes, the membrane was incubated with ${ }^{125}$ I-VEGF 165 ( $\left.2 \mathrm{ng} / \mathrm{ml}\right)$ at room temperature for 2 hours. After three washes, the Far-Western was autoradiographed for 24 hours. Lane 1: $200 \mathrm{ng}$ of recombinant sVEGFR-1 ${ }_{\mathrm{D} 1-5}$; lane 2: 200 ng of recombinant sVEGFR-1 ${ }_{\mathrm{D} 1-6}$; lane 3: free lane; lane 4: $5 \mathrm{ml}$ of concentrated HUVEC-CM; lane $5: 5 \mathrm{ml}$ of concentrated COLO-800-CM. The positions of the protein sizes are indicated on the left. 

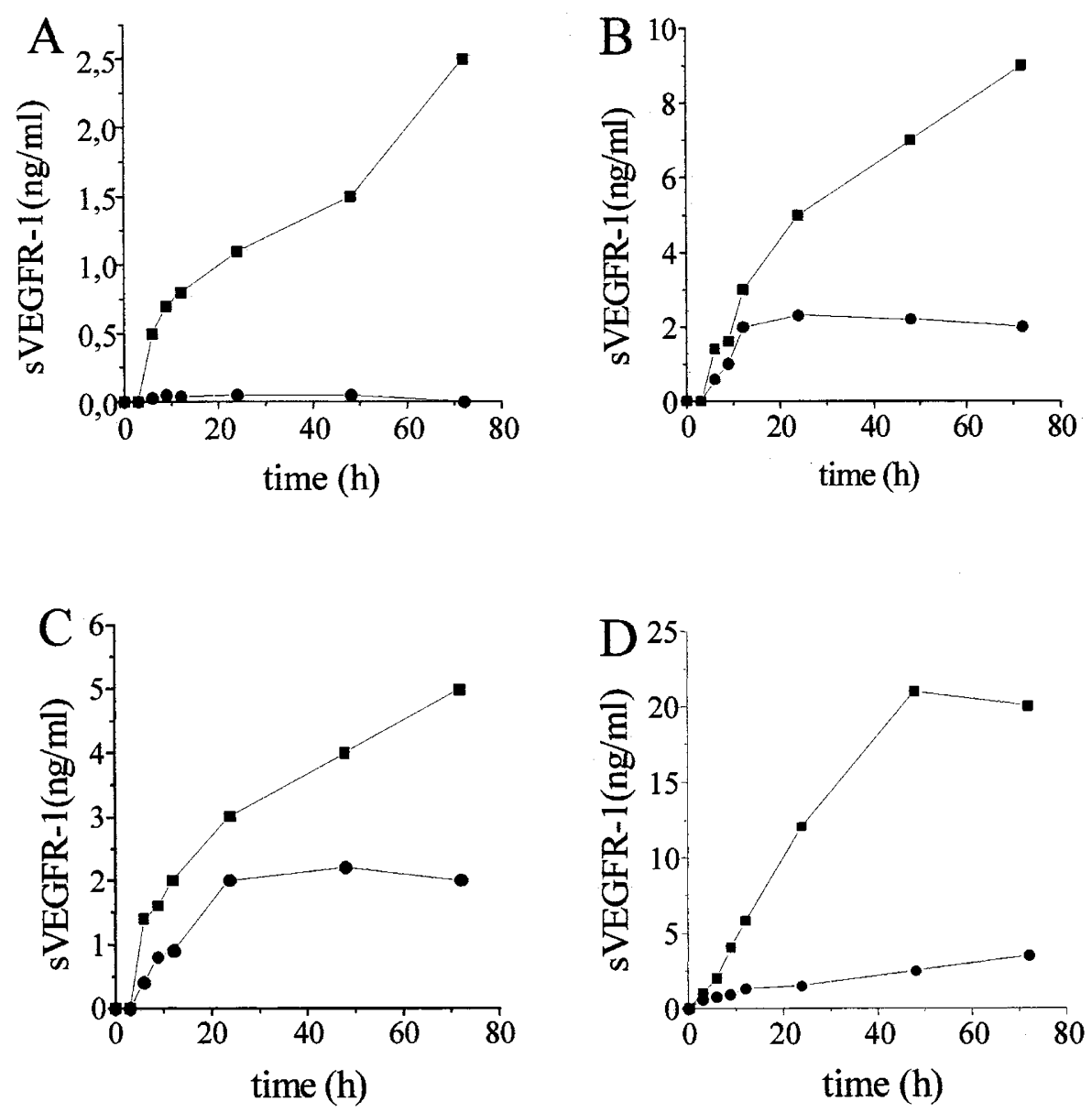

Figure 3.

Time course of sVEGFR-1 release from HUVEC after different stimuli. HUVEC were cultured in basal medium (A), complete growth-medium (B), basal medium containing $20 \mathrm{ng} / \mathrm{ml}$ of bFGF (C), and basal medium containing $20 \mathrm{ng} / \mathrm{ml}$ of PMA (D) for $0,3,6,9,12,24,48$, or 72 hours. The CM were measured in two different ELISAs, which recognize complexed and free SVEGFR-1 (squares) or only free sVEGFR-1 (circles).

$\begin{array}{llllll}0 & 1 & 2 & 4 & 8 & 24 \mathrm{~h}\end{array}$

A

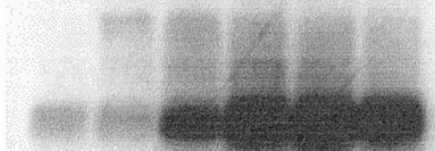

$28 \mathrm{~S}-$

$18 \mathrm{~S}-$



SVEGFR-1

B

VEGFR-1

$\begin{array}{llllll}0 & 1 & 2 & 4 & 8 & 24 \mathrm{~h}\end{array}$



$-28 \mathrm{~S}$

GAPDH

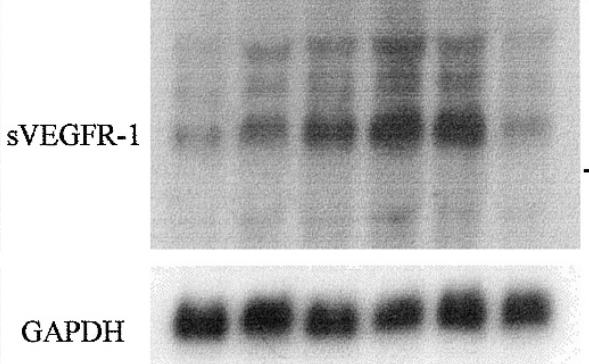

\section{Figure 4.}

Regulation of VEGFR-1 expression by (A) PMA and (B) bFGF. Northern analysis of HUVEC incubated for 24 hours in basal medium and stimulated afterward with (A) $20 \mathrm{ng} / \mathrm{ml}$ of PMA and (B) $10 \mathrm{ng} / \mathrm{ml}$ of bFGF for 1, 2, 4, 8, or 24 hours. The blots contain $8 \mu \mathrm{g}$ of total RNA in each lane. The blots were hybridized with a 1.05 $\mathrm{kb}$ extracellular domain cDNA fragment of VEGFR-1, and a $1.2 \mathrm{~kb}$ cDNA fragment of GAPDH for control. The blots were exposed for 2.5 days.

amounts of VEGF-A (Weindel et al, 1992). The observed levels for VEGF-A were low, remaining in a range between 25 and $150 \mathrm{pg} / \mathrm{ml}$ (Fig. 5A). Interest- ingly, both bFGF-stimulated and PMA-stimulated cells showed a similar pattern: VEGF-A increased up to 24 hours and then decreased again. It was not detectable 

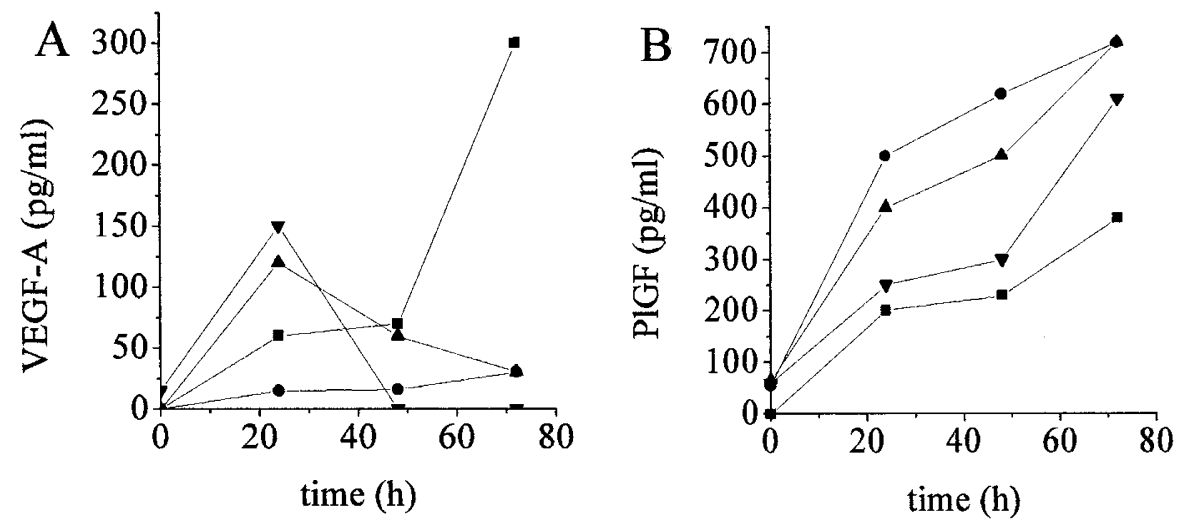

\section{Figure 5.}

Time course of VEGF-A and PIGF release from HUVEC after different stimuli. HUVEC were cultured in basal medium (squares), complete growth medium (circles), basal medium containing $20 \mathrm{ng} / \mathrm{ml}$ of bFGF (up-triangles) and basal medium containing $20 \mathrm{ng} / \mathrm{ml}$ of PMA (down-triangles) for $0,24,48$, or $72 \mathrm{hours}$. The CM were measured in a VEGF-A (A) or PIGF (B) Quantikine-ELISA.

after 72 hours in the case of PMA stimulation, although it was previously shown that VEGF-A expression could be increased by PMA (Wang et al, 1999). It can be observed that low or undetectable amounts of VEGF-A correlate with high amounts of sVEGFR-1. The results for PIGF are shown in Fig. 5B. The levels of PIGF were several-fold higher compared with VEGF-A, and remained nearly unchanged by PMA-stimulation. bFGF-stimulation and complete growth medium led to moderate increases in the PIGF levels. Both VEGF-A and PIGF, as possible ligands of sVEGFR-1, were detected by the ELISA assays in HUVEC-CM. Therefore, we performed immunoprecipitation (IP) studies to detect ligands complexed with sVEGFR-1 (Fig. 6). The antibodies used for precipitation of VEGF-A and PIGF do not cross react with each other (Donnini et al, 1999). We detected complexes with antibodies to VEGF-A and PIGF, indicating a receptor-ligand complex formation between sVEGFR-1 and VEGF-A or PIGF. An antibody to VEGFR-2 used for IP failed to detect possible complexes between proteolytically generated sVEGFR-2 (or sKDR) and sVEGFR-1. This may indicate that no soluble form of VEGFR-2 was generated (by splicing or shedding mechanisms) that could heterodimerize with sVEGFR-1 upon binding of ligands.

The promoter region for VEGFR-1 contains a hypoxia response element, and the receptor can be up-regulated by hypoxia, which is in distinction from VEGFR-2 (Gerber et al, 1997). Therefore, we tested whether hypoxia could affect sVEGFR-1 levels in CM. sVEGFR-1 was immunoprecipitated from placenta villous cell CM (Fig. 7A). Placenta villous cells produced sVEGFR-1 at oxygen levels of $1 \%$ and $5 \%$. The amount of the soluble receptor was clearly decreased when the oxygen level was at $20 \%$ or $40 \%$. The results obtained by IP were confirmed by quantitative measurement of sVEGFR-1 by ELISA (Fig. 7B). The protein levels of sVEGFR-1 in the supernatant of term villous explants were up-regulated under $1 \%$ hypoxia, compared with $5 \%$ oxygen, which is believed to be near normoxia in the placenta (Carter, 1989). In contrast,

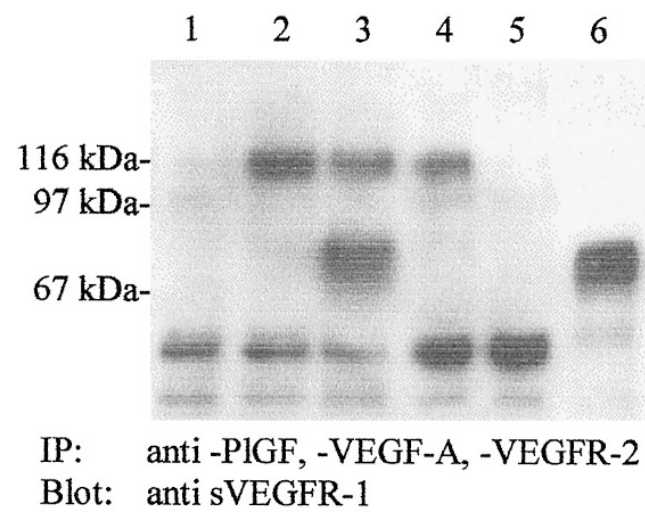

Figure 6.

IP of VEGF-A/PIGF-sVEGFR-1 complexes from HUVEC-CM. Six milliliters of HUVEC-CM from unstimulated cells grown in normal culture medium were used for each IP. After preclearing with a non-specific rabbit serum at a dilution of 1:500, complexes between ligands and sVEGFR-1 were precipitated by incubation with various antibodies for 2 hours at room temperature as follows: rabbit 172 pre-immune serum diluted 1:500 (lane 1); anti-PIGF serum 172 diluted 1:500 (lane 2); anti-PIGF serum 172 diluted 1:500, spiked with 50 ng of recombinant sVEGFR-1 ${ }_{\mathrm{D} 1-5}$ (lane 3); anti-VEGF serum 7 diluted 1:500 (lane 4); anti-VEGFR-2 serum 212 diluted 1:500 (lane 5); $50 \mathrm{ng}$ of recombinant sVEGFR-1 ${ }_{\text {D1-5 }}$ (lane 6). The antibody-receptor/ligand complexes were precipitated by incubation with protein-A agarose for 0.5 hours at room temperature. The pellets were washed twice in PBS and boiled in SDS-PAGE sample buffer. The proteins were separated by $10 \%$ SDS-PAGE and blotted to PVDF membrane. The immunoblot was developed using a monoclonal antisVEGFR-1 antibody and a horseradish peroxidase-conjugated anti-mouse secondary. The positions of the protein sizes are indicated on the left.

under hyperoxia, at $40 \%$ oxygen, the levels of sVEGFR-1 decreased.

\section{Gene Expression of sVEGFR-1 in Different Tissues}

We wanted to analyze which tissues and organs express sVEGFR-1 and its previously identified ligands, VEGF-A, VEGF-B, and PIGF. Therefore, we used a multiple tissue Northern blot for hybridizations. This revealed that placenta contained very strong messages for both the full-length and the soluble VEGFR-1 (Fig. 8). In placenta, VEGF-A message was barely detectable, VEGF-B was expressed moder- 
A

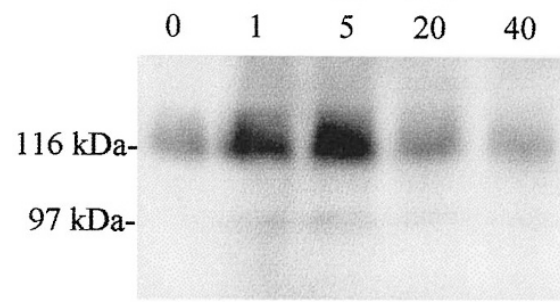

IP: anti sVEGFR-1 polyclonal

Blot: anti sVEGFR-1 monoclonal Flt-11
B

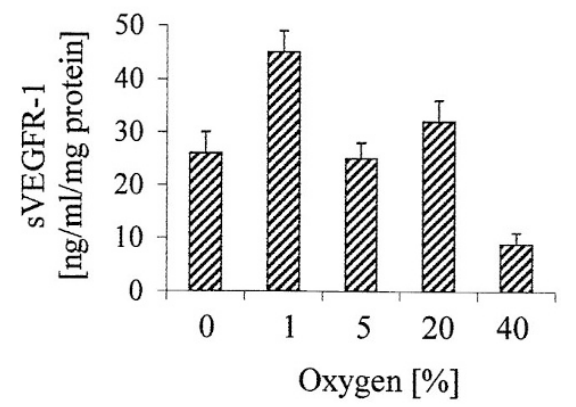

\section{Figure 7.}

Effect of oxygen concentration gradient on SVEGFR-1 levels in CM of cultured placenta villi. IP $(\mathrm{A})$ and determination of sVEGFR-1 content by ELISA (B). $A$, Placenta villous cells were cultured under different oxygen concentrations as indicated. The CM (1 ml each) were used for IPs. After preclearing with rabbit pre-immune serum diluted 1:500, a polyclonal rabbit serum was used diluted 1:500 to precipitate sVEGFR-1. The precipitate was separated by 10\% SDS-PAGE and blotted to PVDF membrane. The immunoblot was developed using a monoclonal antibody to sVEGFR-1 and a horseradish peroxidase-conjugated anti-mouse secondary. The positions of the protein sizes are indicated on the left. $B$, Placenta villi were cultured under increasing oxygen concentrations ( 0 to $40 \%)$, and the CM were assayed for sVEGFR- 1 by ELISA. The results are expressed as mean (+/- SEM) per mg of protein and are a representative of three independent experiments performed in triplicate.

ately, and PIGF showed a very high expression level, comparable to the level of sVEGFR-1 expression. The Northern blotting data for sVEGFR-1 expression in placenta was confirmed by Western blotting analysis of placenta biopsies (data not shown) and was also confirmed with culture supernatants of human placental cells concentrated on a heparin-sepharose column (Fig. 9A). The Western blot showed a strong signal in the first two eluted fractions. A second Western blot, developed with a C-terminal specific anti-sVEGFR-1 serum (Fig. 9B), demonstrated that sVEGFR-1 had the unique $\mathrm{C}$-terminal extension derived from an intron sequence because of the splicing process. The second band for sVEGFR-1 had not been seen before. The shift in size could have been caused by the formation of undissolvable complexes between sVEGFR-1 and heparin that bled from the column.

\section{sVEGFR-1 in Amniotic Fluids Functions as a Sink for VEGF-A and PIGF}

We designed experiments with amniotic fluids, which contain large amounts of endogenous sVEGFR-1 (Hornig et al, 1999), to obtain more information on the possible activity and complex status of sVEGFR-1 harvested from a biological sample. Pooled amniotic fluids $\left(14^{\text {th }}\right.$ to $16^{\text {th }}$ week of gestation) were first measured in both sVEGFR-1 ELISA types. They contained $22 \mathrm{ng} / \mathrm{ml}$ of total sVEGFR-1 and approximately 2 $\mathrm{ng} / \mathrm{ml}$ of free, uncomplexed sVEGFR-1.

The ability to compensate the addition of recombinant external ligands would only be associated with free, uncomplexed receptors. Only free, uncomplexed receptors would have the ability to compensate the addition of recombinant external ligands. To measure the potential to antagonize exogenous growth factor

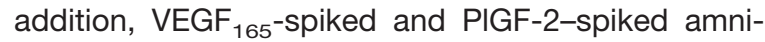
otic fluids were tested for uncomplexed growth factors in VEGF-A and PIGF ELISAs. Normal amniotic fluids were negative for VEGF-A and PIGF. The recovery rate for either growth factors added to sVEGFR- 1-depleted amniotic fluids was approximately $90 \%$. This indicates that both ligands can be measured in amniotic fluids when the soluble receptor protein is not present. Pre-incubation of both ligands with recombinant sVEGFR-1 ${ }_{\mathrm{D} 1-6}$ abolished their detection in both ELISA assays, indicating that both ELISA types do not recognize complexed ligands (Fig. 10A).

To investigate at which ligand concentration the binding activity in amniotic fluids could be saturated, amniotic fluids were spiked with different amounts of recombinant VEGF VE5 $_{165}$ and PIGF-2. Exogenously added VEGF $_{165}$ could not be detected by ELISA measurements at concentrations of 100 to $2500 \mathrm{pg} / \mathrm{ml}$ (Fig. 10B). The recovery of PIGF from supplemented amniotic fluids was reduced by approximately $25 \%$, but from the lowest to the highest supplemented concentration PIGF could be recovered and quantified by our selected assay type. These results demonstrate that amniotic fluids have a differential sink function for the VEGFR-1 ligands, VEGF ${ }_{165}$ and PIGF-2. Moreover, they show to what extent exogenous ligands must be added to compensate for this physiologic sink function.

\section{Discussion}

The present study was aimed at the investigation of clinically relevant but fundamental questions concerning the expression, release, and complex formation of the naturally occurring sVEGFR-1. In 1996, Kendall et al reported the purification of SVEGFR-1 from HUVEC-CM by heparin-sepharose chromatography. The soluble receptor was able to form VEGFdependent heterodimers with recombinant sVEGFR-2 (Kendall et al, 1996). Based on these results, we collected serum-free CM of different cell types known to produce sVEGFR-1. By ELISA measurements, we were able to confirm that $\mathrm{CM}$ from primary microvascular and macrovascular endothelial cell and melanoma cell line contains sVEGFR-1 in different amounts (Hornig et al, 1999). With the Far-Western and cross- 

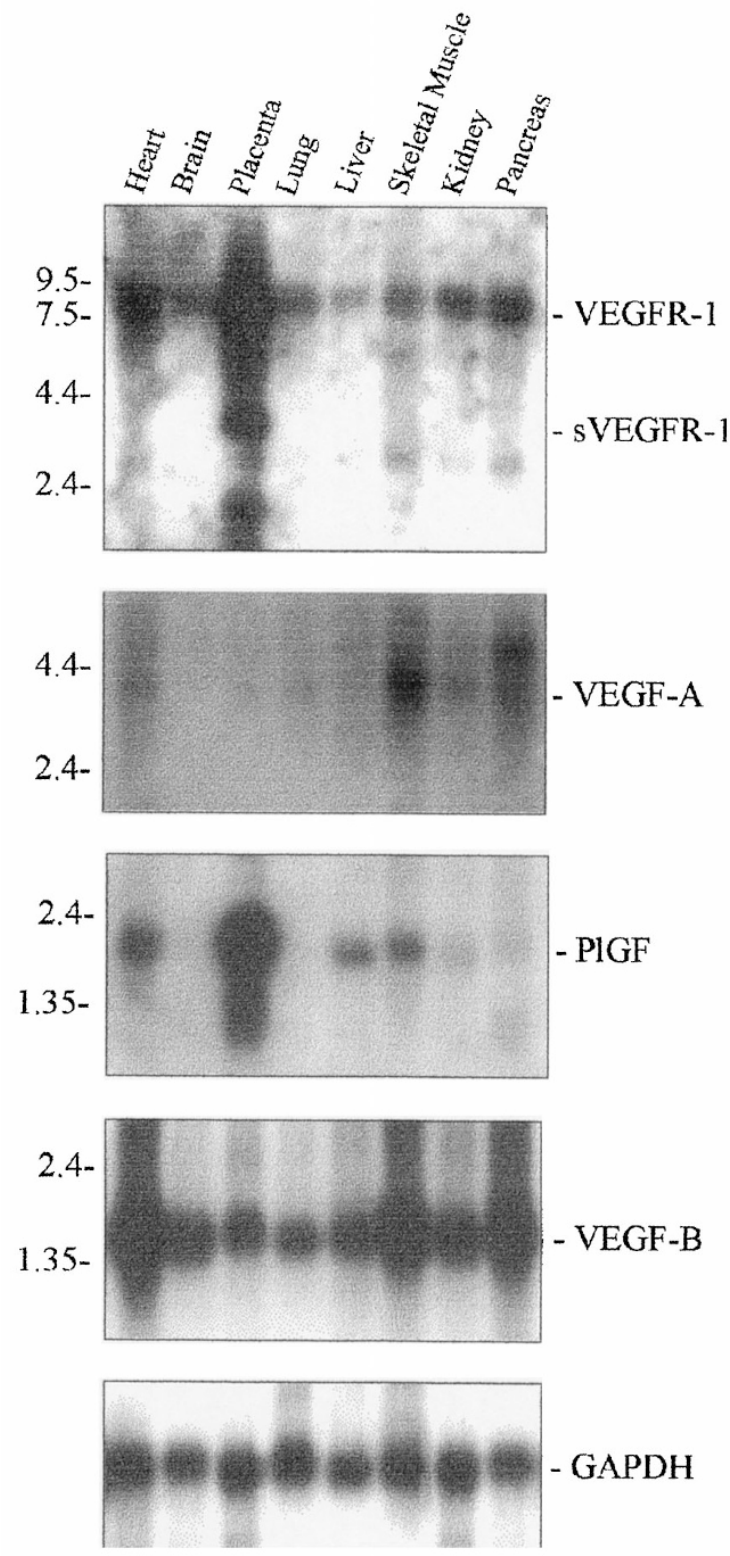

\section{Figure 8.}

Multiple tissue Northern blot showing the expression of SVEGFR-1 and its possible ligands in different human tissues. The blot contains $2 \mu \mathrm{g}$ of poly $\mathrm{A}+$ RNA per lane. cDNA fragments used for hybridization were labeled with ${ }^{32} \mathrm{P}$ as described in Material and Methods. The blot was exposed to Kodak X-OMAT AR films for 2 days (sVEGFR-1, PIGF, VEGF-B) or 1 week (VEGF-A, GAPDH).

linking experiments performed in this study, we show the ability of sVEGFR-1 to bind VEGF ${ }_{165}$. This ligandbinding ability can only be attributed to a free, uncomplexed receptor. The results indicate that at least a portion of sVEGFR-1 in cell culture supernatants must be uncomplexed. The molecular weight of sVEGFR-1 from HUVEC-CM, deduced from the Far-Western and cross-linking experiments, is approximately $110 \mathrm{kd}$, which is in agreement with previous findings (Kendall et al, 1996). The sVEGFR-1 from COLO-800-CM seemed to have a higher molecular weight, this was shown to be an effect of a different glycosylation pattern. After deglycosylation, both HUVEC-derived and COLO-800-derived SVEGFR-1 had the same size.

With time course experiments and quantitative ELISA measurements in two assay types, we described the kinetics of sVEGFR-1 release from HUVEC and differentiated between the amount of total (complexed and free) and free sVEGFR-1 in the CM. We showed, for the first time, that sVEGFR-1 in CM is mainly complexed. In IP studies, we detected complexes between sVEGFR-1 and VEGF-A or PIGF. Heterodimers between putative proteolytically generated sVEGFR-2 and naturally occurring sVEGFR-1 were not observed in these experiments.

Gerber et al (1997) have shown that the VEGFR-1 promoter contains hypoxia response elements, and that the expression rate of reporter constructs can be increased by hypoxia. This is very similar to the VEGF-A gene, which also is strongly up-regulated by hypoxia (Shweiki et al, 1992). As sVEGFR-1 is a splice variant of the flt-1 gene, it can be supposed that its expression can also be regulated by hypoxia. Our IP experiments with placenta villous cell-CM clearly demonstrated a regulation of SVEGFR-1 expression by hypoxia. The protein levels of sVEGFR-1 in the supernatants of term villous explants were upregulated under $1 \%$ oxygen hypoxia compared with $5 \%$ oxygen, which is believed to be near normoxia in the placenta (Carter et al, 1989). In contrast, under hyperoxia (at $40 \%$ oxygen), the levels of sVEGFR-1 decreased. A recent study showed that PIGF is upregulated and VEGF-A levels are decreased in severe intra-uterine growth retardation (Khaliq et al, 1999), which may exhibit a hyperoxic state (see commentary, Ahmed and Kilby, 1997). The decrease of sVEGFR-1 under hyperoxia, seen in the present study, suggests that the action of PIGF would be unopposed, thus amplifying the deleterious effect of PIGF on placental growth and development as seen in intra-uterine growth retardation.

We found a strong expression of the flt-1 gene in placental cells and were able to detect the sVEGFR-1 protein in Western blot analysis with a specific antisVEGFR-1 serum (Hiratsuka et al, 1998) that binds an epitope in the unique 31-amino acid C-terminal extension. These amino acids are derived from an intron sequence and are specific for sVEGFR-1 (Kendall and Thomas, 1993; Kendall et al, 1996). Therefore, we conclude that the sVEGFR-1 detected in our experiments was mainly the product of differential splicing. However, we can not exclude the possibility that it was partially generated by the action of matrix proteases.

We have previously reported that amniotic fluids of different gestational age contain high levels of sVEGFR-1 (Hornig et al, 1999). The source and function of the sVEGFR-1 in the amniotic fluids is still unknown. However, it is likely to function as a sink for excess growth factors (like VEGF-A or PIGF) diffusing in from the placenta and forming complexes with sVEGFR-1. Complex formation would abolish the biological activities of these growth factors. After spiking amniotic fluids with recombinant PIGF or VEGF-A, 


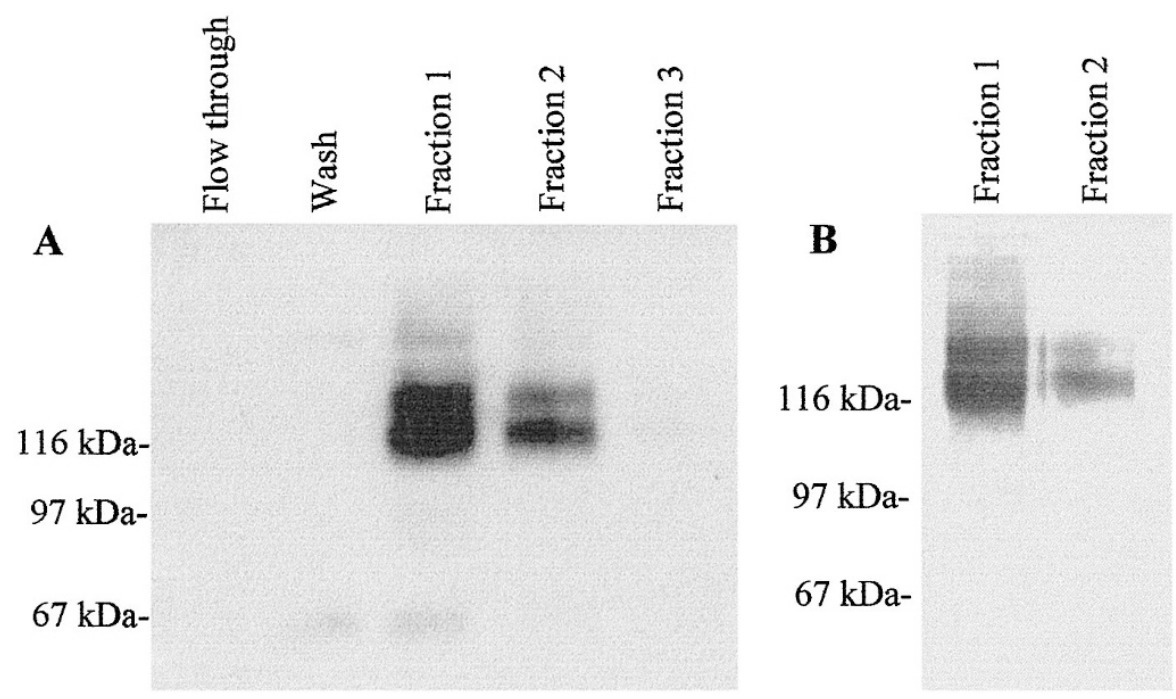

\section{Figure 9.}

CM of placenta cells from biopsies contain SVEGFR-1. Five milliliters of CM were adjusted to $0.5 \mathrm{M} \mathrm{NaCl}$ and run over a $1 \mathrm{ml}$ HiTrap heparin-sepharose column. After washing the column with PBS containing $0.5 \mathrm{M} \mathrm{NaCl}$, bound proteins were eluted with PBS containing $1.5 \mathrm{M} \mathrm{NaCl}$, and $1 \mathrm{ml}$ fractions were collected. The fractions were concentrated by TCA-precipitation and separated by $10 \%$ SDS-PAGE. After blotting onto PVDF membrane, the blots were incubated with the mouse monoclonal VEGFR-1 antibody, FLT-11 (A) or the polyclonal, C-terminal-specific anti-sVEGFR-1 serum $\alpha \mathrm{S}$ (B). A horseradish peroxidase-conjugated anti-mouse secondary (A) and an alkaline phosphatase-conjugated anti-rabbit secondary (B) were used. The positions of the protein sizes are indicated on the left.
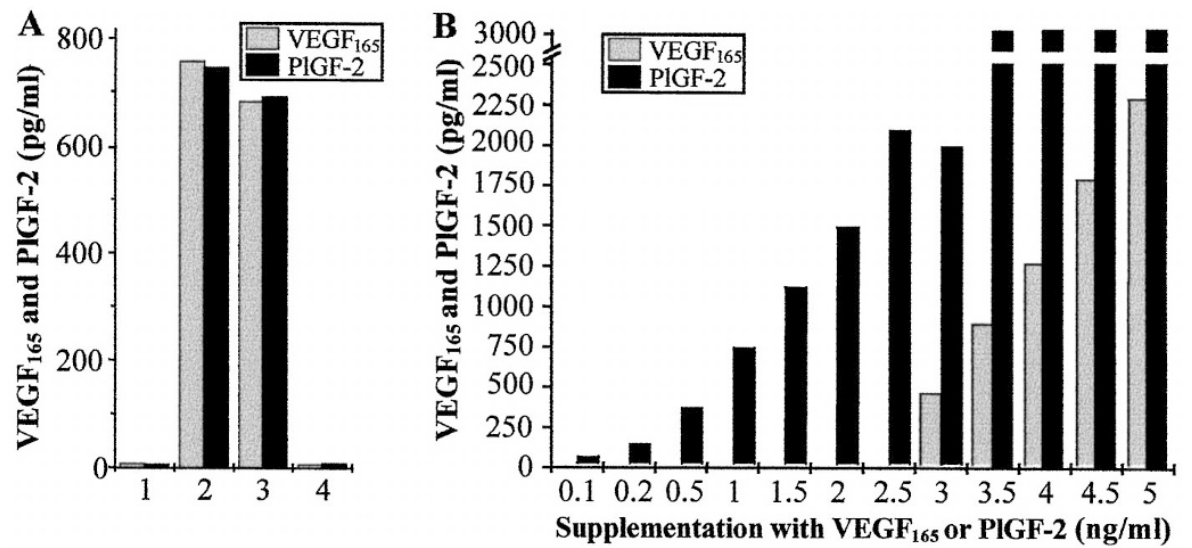

Figure 10.

Quantification of sVEGFR-1 ligands after compensation for the amniotic fluids sink function with exogenous recombinant VEGF ${ }_{165}$ or PIGF-2. For the determination of the VEGF ${ }_{165}$ or PIGF-2 binding activity in amniotic fluids, amniotic fluids were spiked with recombinant VEGF 165 or PIGF-2 and tested after 1 hour of pre-incubation for VEGF 165 and PIGF-2 recovery in ELISA. Both ELISAs recognized only free, uncomplexed growth factors. A, Controls: Amniotic fluids without addition of growth factors (column 1); $750 \mathrm{pg} / \mathrm{ml}$ of recombinant growth factors in PBS (column 2); sVEGFR-1-depleted amniotic fluids spiked with $750 \mathrm{pg} / \mathrm{ml}$ of recombinant growth factors (column 3); $750 \mathrm{pg} / \mathrm{ml}$ of recombinant growth factors pre-incubated for 1 hour with a 50 -fold excess of recombinant sVEGFR-1 Supplementation of amniotic fluids with increasing amounts of $\mathrm{VEGF}_{165}$ or PIGF, and measurement of growth factor recovery in ELISA after 1 hour of pre-incubation.

we tested the recovery of both growth factors in ELISA. Based on the ELISA experiments, it was shown that SVEGFR-1 in amniotic fluids can bind and complex up to $3 \mathrm{ng} / \mathrm{ml}$ of VEGF ${ }_{165}$. The VEGF-A binding activity of amniotic fluids has been previously observed (Banks et al, 1998). Furthermore, it was demonstrated that amniotic fluids and sera of pregnant women have distinct and pregnancy time-point related VEGF-A binding capacities (Vuorela-Vepsäläinen et al, 1998). A naturally occurring secreted protein with strong VEGF-A binding activity would have the potency to antagonize the VEGF-A actions and to participate in the regulation of angiogenesis. It is evident that VEGF-A levels rise in the maternal circulation during pregnancy (Anthony et al, 1997; Clark and Charnock-Jones, 1999), but there is also an increase in sVEGFR-1 (Banks et al, 1998). Thus, sVEGFR-1 may participate in a paracrine mode to regulate local angiogenesis and to avoid a local or systemic overshooting response to VEGF-A.

Homodimeric PIGF, which is produced by the placenta at high levels, was also shown to bind to VEGFR-1, although it had a lower affinity $\left(K_{d} \sim 250\right.$ pM) than VEGF-A ( $K_{d} \sim 10$ to $20 \mathrm{pm}$ ) (Ferrara and Davis-Smyth, 1997; Park et al, 1994). Surprisingly, normal amniotic fluids do not contain detectable PIGF or VEGF-A, which may indicate, per se, that both ligands are complexed to carrier proteins. In our study, 
we observed that the amounts of exogenously added PIGF bound by sVEGFR-1 in amniotic fluids were 10 -fold lower than the amounts of $\mathrm{VEGF}_{165}$. A possible reason for this could be the lower affinity of PIGF for VEGFR-1.

Several extracellular molecules influence the angiogenic balance in a positive or negative way. Among these molecules, sVEGFR-1 represents an endogenous fragment of a full-length receptor, which is normally associated with ongoing angiogenic processes. The regulation of switching the transcription from the transmembrane to the soluble form of VEGFR-1 is not yet clear, but it was shown that in mouse placenta, the expression of both transmembrane and soluble VEGFR-1 changed during the progression of pregnancy (He et al, 1999). The mode of action of sVEGFR-1 may be similar to angiopoietin-2, which is a competitive inhibitor for the binding of angiopoietin-1 to the receptor tie-2 (Maisonpierre et al, 1997). Both angiopoietin-2 and sVEGFR-1 represent naturally occurring, endogenous antagonists that block the activation of receptor-tyrosine kinases. Angiopoietin-2 and sVEGFR-1 are produced by endothelial cells acting in an autocrine fashion. sVEGFR-1 can sequester VEGF in the microenvironment of the endothelial cells. Furthermore, sVEGFR-1 may also form heterodimers with the two membrane bound VEGF-A receptors, leading to a dominant negative receptor inhibition by abolishing receptor autophosphorylation.

\section{Materials and Methods}

\section{Cell Culture}

Primary HUVEC (BioWhittaker, Walkersville, Maryland) and primary human dermal microvascular endothelial cells (MVEC, BioWhittaker) were cultured in endothelial growth medium (endothelial basal medium [EBM]), $5 \%$ fetal calf serum (FCS), growth factor supplements; Bio Whittaker). Cells from passages 4 to 8 were used in the experiments. The melanoma cell line, COLO800 (DSMZ, Braunschweig, Germany), was cultured in RPMI 1640 medium (GIBCO BRL, Karlsruhe, Germany) with $5 \%$ FCS. All cells were kept at $37^{\circ} \mathrm{C}$ with $5 \% \mathrm{CO}_{2}$.

\section{Generation of CM}

Cell cultures that were $80 \%$ confluent were washed twice with $\mathrm{PBS}$ and were then incubated in serum-free media (GIBCO BRL) for 48 to 72 hours to generate serum-free supernatants. The supernatants were centrifuged for 10 minutes at $1500 \times g$ and frozen at $-20^{\circ} \mathrm{C}$.

\section{Time Course Experiments}

Supernatants for time course experiments were generated in 48 well dishes (Costar, New York). HUVEC were seeded at a density of 5000 cells/well and incubated in endothelial growth medium until confluent. After washing twice in PBS, the cells were grown for $3,6,9,12,24,48$, or 72 hours in basal medium (EBM with 1\% FCS), growth-medium, basal medium containing $20 \mathrm{ng} / \mathrm{ml}$ of basic fibroblast growth factor (bFGF; Sigma, Munich, Germany), or basal medium supplemented with $20 \mathrm{ng} / \mathrm{ml}$ of phorbol-myristateacetate (PMA; Sigma). After harvesting, the supernatants were centrifuged and stored immediately at $-20^{\circ} \mathrm{C}$ until further usage.

\section{Placenta Biopsy Supernatants}

A pool $(n=20)$ of culture media from placental biopsies was used for Western blot analysis. The biopsies were conducted in accordance with the guidelines and approval given by the Ethical Committee of the Department of Obstetrics and Gynecology of the Helsinki University Central Hospital, Helsinki, Finland. The biopsies, performed at gestational weeks 10 to 12 for assessment of fetal chromosomes from women over 40 years old, showed normal karyotypes for all samples. Biopsy specimens were cultured in 5 $\mathrm{ml}$ of Chang medium (Irvine Scientific, Santa Ana, California) at $37^{\circ} \mathrm{C}$ and $5 \% \mathrm{CO}_{2}$ for 10 to 14 days. The pool of culture media was stored at minus $20^{\circ} \mathrm{C}$ until analysis.

\section{Villous Culture Under Increasing Oxygen Tension}

Placenta villous tissue explants were obtained from the fetal side of Caesarian sections and cultured under increasing oxygen tension as previously described (Khaliq et al, 1999). In brief, blood vessels were removed from the explants and the villous fragments were equilibrated overnight in phenol-free DMEM containing $0.1 \%$ FCS. Tissue culture flasks containing near-confluent cells were transferred to Modular Incubator chambers (ICN, Thame, Oxfordshire, United Kingdom) that were subsequently purged with gas mixtures comprised of $0 \%, 1 \%, 5 \%, 20 \%$, or $40 \%$ oxygen supplemented with $5 \% \mathrm{CO}_{2}$ with a balance of nitrogen for 5 minutes. After 24 hours of exposure to various oxygen concentrations, media were removed and immediately frozen at $-20^{\circ} \mathrm{C}$.

\section{Amniotic Fluids}

Amniotic fluids were collected from healthy pregnant women during amniocentesis by the Braunschweig City Hospital, Braunschweig, Germany, in accordance with the guidelines and approval given by the Ethical Committee of the Medical School Hannover, Hannover, Germany. Only leftovers of diagnostic samples were used. The samples were stored at $-20^{\circ} \mathrm{C}$ until usage. For measurement in ELISA, the amniotic fluids were desalted on NAP-5 columns (PharmaciaBiotech, Uppsala, Sweden) and eluted with PBS directly before use. For some experiments, sVEGFR-1 was depleted from amniotic fluids by size exclusion filtration $<30 \mathrm{kd}$ (Amicon, Beverly, Massachusetts).

\section{Northern Analysis}

Total RNA was prepared using Trizol reagent (GIBCO $\mathrm{BRL}$ ) according to the manufacturer's instructions. 
The RNA was separated on formaldehyde-containing agarose gels, transferred to nitrocellulose membranes, and hybridized to ${ }^{32} \mathrm{P}$-labeled cDNA fragments (Sambrook et al, 1989). The multiple-tissue Northern blot (Clontech, Palo Alto, California) was used according to the manufacturer's instructions. For hybridization, cDNA fragments of VEGFR-1 and VEGF (Barleon et al, 1994), VEGF-B, PIGF, and GAPDH (Donnini et al, 1999) were labeled with $\alpha^{32} \mathrm{P}$-dATP (Amersham-Pharmacia, Freiburg, Germany) with the Prime-a-Gene Labeling System (Promega, Madison, Wisconsin) according to the manufacturer's instructions.

\section{Recombinant Proteins and Antibodies}

Recombinant human sVEGFR-1 ${ }_{\mathrm{D} 1-5}$, sVEGFR-1 ${ }_{\mathrm{D} 1-6}$, VEGF $_{165}$, and PIGF-2 were produced in insect cells and purified as previously described (Fiebich et al, 1993; Hauser and Weich 1993; Röckl et al, 1998). The generation of the rabbit polyclonal anti-VEGFR-1 791 serum used for ELISA and IP has been previously described (Hornig et al, 1999). The mouse monoclonal VEGFR-1 antibody, FLT-11 (Sigma), and the rabbit polyclonal, C-terminal-specific anti-sVEGFR-1 serum, $\alpha \mathrm{S}$ (Hiratsuka et al, 1998) were used for immunoblotting. The polyclonal sera anti-VEGF 7, anti-PIGF 172, and anti-KDR 212 were used for IP and were described in detail previously (Donnini et al, 1999; Röckl et al, 1998).

\section{ELISA Measurement}

The ELISA for the quantification of complexed and free sVEGFR-1 was previously described (Hornig et al, 1999). The ELISA recognizing only uncomplexed, free sVEGFR-1 was newly developed for this study. It follows the protocol of the sVEGFR-1 ELISA (Hornig et al, 1999), except that plates were coated with $2 \mu \mathrm{g} / \mathrm{ml}$ of sVEGFR-1 binding protein that recognizes no ligand-complexed forms. For detection, the mouse monoclonal antibody FLT-352.1 was used, at a dilution of $1: 1000$.

The Quantikine ELISAs for VEGF-A and PIGF were purchased from $R$ and D Systems Europe (Abingdon, United Kingdom). The VEGF-A ELISA recognizes only free, uncomplexed VEGF (Banks et al, 1998). Similar to the VEGF-A ELISA, the PIGF ELISA does not recognize PIGF bound to sVEGFR-1 $(\mathrm{CH}$, unpublished results). For measurement of the sink function, amniotic fluids were spiked with recombinant $V E_{165}$ or PIGF-2 and pre-incubated for 1 hour at room temperature. The recovery of VEGF-A or PIGF was determined in the R and D Systems Europe ELISAs according to the manufacturer's instructions.

\section{Pretreatment of Supernatants}

For immunoblotting, serum-free tissue culture supernatants were concentrated by incubation with a heparin-sepharose slurry (Pharmacia-Biotech). Five milliliters of supernatants were adjusted to $0.5 \mathrm{M} \mathrm{NaCl}$ and incubated for 2 hours at room temperature with 50 $\mu l$ of heparin-sepharose slurry on a shaker platform. After centrifugation at $1500 \times \mathrm{g}$ for 10 minutes, the pellets were washed with PBS and incubated for 5 minutes at $95^{\circ} \mathrm{C}$ in $20 \mu \mathrm{l}$ of SDS-PAGE sample buffer, or for 10 minutes at $37^{\circ} \mathrm{C}$ in SDS-PAGE sample buffer without mercaptoethanol. Placenta cell supernatants were concentrated on a $1 \mathrm{ml}$ HiTrap heparinsepharose column (Pharmacia-Biotech) before TCA precipitation as previously described for concentration of amniotic fluids (Hornig et al, 1999). For deglycosylation, the CM were pretreated and incubated with N-glycosidase F (Boehringer-Mannheim, Mannheim, Germany) according to the manufacturer's instructions.

\section{IP}

For IP of sVEGFR-1 from HUVEC-CM or placenta villous cell culture supernatants, all samples were first incubated for 1 hour at room temperature with a non-specific rabbit pre-immune serum at a dilution of 1:500 for preclearing. After incubation with $2 \mu \mathrm{l}$ of protein A agarose (Sigma) for 0.5 hours at room temperature, the agarose was precipitated by centrifugation for 10 minutes at $20,000 \times g$ at room temperature. The supernatant was transferred to a new cup and the polyclonal sera 7 (anti-VEGF-A), 172 (antiPIGF), 212 (anti-VEGFR-2), or 791 (anti-VEGFR-1) were added at a dilution of 1:500 and incubated for 1 hour at room temperature. The antibody/antigen complexes were precipitated by incubation with protein $A$ agarose and centrifugation as previously described. The pellets were washed twice in PBS and incubated for 5 minutes at $95^{\circ} \mathrm{C}$ in reducing SDS-PAGE sample buffer.

\section{SDS-PAGE and Western Blot}

The proteins were separated in a 10\% SDS-PAGE and semi-dry blotted to PVDF membrane (Hornig et al, 1999; Röckl et al, 1998). The immunoblots were incubated with the mouse monoclonal sVEGFR-1 antibody, FLT-11 (Sigma), followed by incubation with either alkaline phosphatase-conjugated or horseradish peroxidase-conjugated secondary antibodies (Promega).

\section{Far-Western Studies}

For Far-Western experiments, $5 \mathrm{ml}$ of HUVEC or COLO-800 cell supernatants were concentrated by incubation with a heparin-sepharose slurry as described above. The pellets and recombinant sVEGFR-1 proteins were incubated in non-reducing SDS-PAGE loading buffer and separated by $10 \%$ SDS-PAGE. After semi-dry blotting and saturation of the PVDF membrane with $20 \%$ low-fat milk, the membrane was incubated for 2 hours at room temperature in binding buffer with $2 \mathrm{ng} / \mathrm{ml}$ of ${ }^{125}{\mathrm{I}-V} \mathrm{EGF}_{165}$ (Röckl et al, 1998). Unspecific binding was removed by three washes in binding buffer. The membrane was air-dried and exposed overnight to X-ray films (X-OMAT AR, Kodak, Rochester, New York). 


\section{Cross-Linking Experiments}

For cross-linking experiments, $5 \mathrm{ml}$ of HUVEC or COLO-800 cell supernatants were concentrated by incubation with heparin-sepharose slurry as described above. Bound proteins were dissolved from the heparin-sepharose pellet by incubation with $40 \mu \mathrm{l}$ of PBS containing $1 \mathrm{M} \mathrm{NaCl}$. Before cross-linking, the 40 $\mu$ l samples were dialyzed against PBS on filter membranes (pore-size $0.025 \mu \mathrm{m}$; Millipore, Bedford, Massachusetts). Recombinant sVEGFR-1 proteins and sVEGFR-1 from CM were incubated with $1 \mathrm{ng} / \mathrm{ml}$ of ${ }^{125}$ I-VEGF ${ }_{165}$ for 2 hours at room temperature. Crosslinking was carried out as previously described (Röckl et al, 1998). The covalently linked complexes were separated by $7.5 \%$ non-reducing SDS-PAGE. After air-drying, the gel was exposed overnight to X-ray films.

\section{Acknowledgement}

We thank Dr. Hellmut Augustin for critically reading the manuscript and Ms. Tanja Behn for excellent technical assistance. We are grateful to Drs. Kari Alitalo and Masabumi Shibuya for providing us with the VEGF-B cDNA and the anti-soluble VEGFR-1 $(\alpha S)$ serum. The mouse monoclonal antibody, 352.1, was developed with the help and expertise of Dr. Dorit Zharhary (Sigma, Israel). We thank Dr. Wolfgang Bartsch for the collection of the amniotic fluid samples.

\section{References}

Ahmed A and Kilby MD (1997). Placental insufficiency: Hypoxia or hyperoxia? Lancet 350:826-827.

Ahmed A, Dunk C, Kniss D, and Wilkes M (1997). Role of VEGFR-1 (Flt-1) in mediating calcium-dependent nitric oxide release and limiting DNA synthesis in human trophoblast cells. Lab Invest 76:779-791.

Anthony FW, Evans PW, Wheeler T, and Wood PJ (1997). Variation in detection of VEGF in maternal serum by immunoassay and the possible influence of binding proteins. Ann Clin Biochem 34:276-280.

Banks RE, Forbes MA, Searles J, Pappin D, Canas B, Rahman D, Kaufmann S, Walters CE, Jackson A, Eves P, Linton G, Keen J, Walker JJ, and Selby PJ (1998). Evidence for the existence of a novel pregnancy associated soluble variant of the vascular endothelial growth factor receptor, Flt-1. Mol Hum Reprod 4:377-386.

Barleon B, Hauser S, Schöllmann C, Weindel K, Marmè D, Yayon A, and Weich HA (1994). Differential expression of the two VEGF receptors flt and KDR in placenta and vascular endothelial cells. J Cell Biochem 54:56-66.

Barleon B, Totzke F, Herzog C, Blanke S, Kremmer E, Siemeister G, Marmè D, and Martiny-Baron G (1997). Mapping of the sites for ligand binding and receptor dimerization at the extracellular domain of the vascular endothelial growth factor receptor FLT-1. J Biol Chem 272:10382-10388.

Boocock CA, Charnock-Jones DS, Sharkey AM, McLaren J, Barker PJ, Wright KA, Twentyman PR, and Smith SK (1995). Expression of vascular endothelial growth factor and its receptors flt and KDR in ovarian carcinoma. J Natl Cancer Inst 87:506-516.
Clark DE and Charnock-Jones DS (1999). Placental angiogenesis: The role of the VEGF family of proteins. Angiogenesis 2:309-318.

Carter AM (1989). Factors affecting gas transfer across the placenta and the oxygen supply to the fetus. J Dev Physiol 12:305-322.

Clauss M (1998). Functions of the VEGFR-1 (FLT-1) in the vasculature. Trends Cardiovasc Med 8:241-245.

Donnini S, Machein MR, Plate KH, and Weich HA (1999). Expression and localization of placenta growth factor and PIGF receptors in human meningiomas. J Pathol 189:66-71.

Ferrara N and Davis-Smyth T (1997). The biology of vascular endothelial growth factor. Endocrinol Rev 18:4-25.

Fiebich BL, Jäger B, Schöllmann C, Weindel K, Wilting J, Kochs G, Marmè D, Hug H, and Weich HA (1993). Synthesis and assembly of functionally active human vascular endothelial growth factor homodimers in insect cells. European J Biochem 211:19-26.

Flamme I, Frölich T, and Risau W (1997). Molecular mechanisms of vasculogenesis and embryonic angiogenesis. J Cell Physiol 173:206-210.

Fong GH, Rassant J, Gertenstein M, and Breitman M (1995). Role of Flt-1 receptor tyrosine kinase in regulation of assembly of vascular endothelium. Nature 376:66-67.

Gabrilovich DI, Chen HL, Girgis KR, Cunningham HT, Meny GM, Nadaf S, Kavanaugh D, and Carbone DP (1996). Production of vascular endothelial growth factor by human tumours inhibits the functional maturation of dendritic cells. Nat Med 2:1096-1103.

Gerber HP, Condorelli F, Park J, and Ferrara N (1997). Differential transcriptional regulation of the two vascular endothelial growth factor receptor genes. J Biol Chem 272: 23659-23667.

Hauser S and Weich HA (1993). A heparin-binding form of placenta growth factor (PIGF-2) is expressed in human umbilical vein endothelial cells and in placenta. Growth Factors 9:259-268.

He Y, Smith SK, Day KA, Clark DE, Licence DR, and Charnock-Jones DS (1999). Alternative splicing of vascular endothelial growth factor (VEGF)-R1 (FIt-1) pre-mRNA is important for the regulation of VEGF activity. Mol Endocr 13:537-545.

Hiratsuka S, Minowa O, Kuno J, Noda T, and Shibuya M (1998). Flt-1 lacking the tyrosine kinase domain is sufficient for normal development and angiogenesis in mice. Proc Natl Acad Sci USA 95:9349-9354.

Hornig C, Behn T, Bartsch W, Yayon A, and Weich HA (1999). Detection and quantification of complexed and free soluble human vascular endothelial growth factor receptor-1 (sVEGFR-1) by ELISA. J Immunol Meth 226:169-177.

Kendall RL and Thomas KA (1993). Inhibition of vascular endothelial cell growth factor activity by an endogenously encoded soluble receptor. Proc Natl Acad Sci USA 90: 10705-10709.

Kendall RL, Wang G, and Thomas KA (1996). Identification of a natural soluble form of the vascular endothelial growth factor receptor FLT-1 and its heterodimerization with KDR. Biochem Biophys Res Commun 226:324-328. 
Khaliq A, Dunk CE, Shams M, Li XF, Whittle MJ, Weich $H$, and Ahmed A (1999). Hypoxia down-regulates placenta growth factor whereas fetal growth restriction up-regulates placenta growth factor expression: Molecular evidence for placental hyperoxia in intrauterine growth restriction. Lab Invest 79:151-170.

Kondo K, Hiratsuka S, Subbalakshmi E, Matsushime H, and Shibuya M (1998). Genomic organization of the flt-1 gene encoding for vascular endothelial growth factor (VEGF) receptor-1 suggests an intimate evolutionary relationship between the 7-lg and the 5-lg tyrosine kinase receptors. Gene 208:297-305.

Leung DW, Cachianes G, Kuang WJ, Goeddel DV, and Ferrara N (1989). Vascular endothelial growth factor is a secreted angiogenic mitogen. Science 246:1306-1309.

Maisonpierre PC, Suri C, Jones PF, Bartunkova S, Wiegand SJ, Radcziejewski C, Compton D, McLain J, Aldrich TH, Papadopoulos N, Daly TJ, Davis S, Sato TN, and Yancopoulos GD (1997). Angiopoietin-2, a natural antagonist for Tie-2 that disrupts in vivo angiogenesis. Science 277:55-60.

Olofsson B, Korpelainen E, Pepper MS, Mandriota SJ, Aase K, Kumar V, Gunji Y, Jeltsch MM, Shibuya M, Alitalo K, and Eriksson U (1998). Vascular endothelial growth factor B (VEGF-B) binds to VEGF receptor-1 and regulates plasminogen activator activity in endothelial cells. Proc Natl Acad Sci USA 95:11709-11714.

Pajusola K, Aprelikova O, Korhonen J, Kaipainen A, Pertovaara L, Alitalo R, and Alitalo K (1992). FLT4 receptor tyrosine kinase contains seven immunoglobulin-like loops and is expressed in multiple human tissues and cell lines. Cancer Res 52:5738-5743.

Park JE, Chen HH, Winer J, Houck KA, and Ferrara N (1994). Placenta growth factor. Potentiation of vascular endothelial growth factor bioactivity, in vitro and in vivo, and high affinity binding to Flt-1 but not to Flk-1/KDR. J Biol Chem 269: 25646-25654.

Röckl W, Hecht D, Sztajer H, Waltenberger J, Yayon A, and Weich HA (1998). Differential binding characteristics and cellular inhibition by soluble VEGF receptors 1 and 2 . Exp Cell Res 241:161-170.

Sambrook J, Fritsch EF, and Maniatis T (1989). Molecular cloning: A laboratory manual. $2^{\text {nd }}$ edition. Cold Spring Harbour Laboratory, New York.
Seetharam L, Gotoh N, Maru Y, Neufeld G, Yamaguchi S, and Shibuya M (1995). A unique signal transduction pathway for the FLT tyrosine kinase, a receptor for vascular endothelial growth factor. Oncogene 10:135-147.

Shalabi F, Rossant J, Yamaguchi TP, Gertenstein M, Wu XF, Breitman ML, and Shuh AC (1995). Failure of blood island formation and vasculogenesis in Flk-1 deficient mice. Nature 376:62-66.

Shibuya M, Yamaguchi S, Yamane A, Ikeda T, Tojo A, Matsushime H, and Sato M (1990). Nucleotide sequence and expression of a novel human receptor-type tyrosine kinase gene (flt) closely related to the fms family. Oncogene 5:519524.

Shweiki D, Itin A, Soffer D, and Keshet E (1992). Vascular endothelial growth factor induced by hypoxia may mediate hypoxia-initiated angiogenesis. Nature 359:843-845.

Terman B, Dougher-Vermazen M, Carrion ME, Dimitrov D, Armellino DC, Gospodarowicz D, and Bohlen P (1992). Identification of the KDR tyrosine kinase as a receptor for vascular endothelial cell growth factor. Biochem Biophys Res Commun 187:1579-1586.

Terman BI, Khandke L, Dougher-Vermazan M, Maglione D, Lassam NJ, Gospodarowicz D, Persico MG, Bohlen P, and Eisinger M (1994). VEGF receptor subtypes KDR and Flt-1 show different sensitivities to heparin and placenta growth factor. Growth Factors 11:187-195.

Vuorela-Vepsäläinen $\mathrm{P}$, Alfthan $\mathrm{H}$, Orpana A, Alitalo K, Stenman UH, and Halmesmäki E (1998). Vascular endothelial growth factor is bound in amniotic fluid and maternal serum. Hum Reprod 14:1346-1351.

Wang D, Huang HJS, Kazlauskas A, and Cavenee WK (1999). Induction of vascular endothelial growth factor expression in endothelial cells by platelet-derived growth factor through the activation of phosphatidylinositol 3-kinase. Cancer Res 59:1464-1472.

Weindel K, Marmé D, and Weich HA (1992). Aids-associated Kaposis sarcoma cells in culture express vascular endothelial growth factor. Biochem Biophys Res Commun 183:11671174 . 